\title{
Reintroducing Indonesian Traditional Games through an Interactive Multiplayer Table Game - Gobak Sodor
}

\author{
Emanuel Pratalaharja \\ Binus Northumbria School of Design \\ Graphic Design and New Media \\ Bina Nusantara University \\ Jakarta, Indonesia \\ emanuel.pratalaharja@gmail.com
}

\author{
Bayu Prakoso Dirgantoro \\ Binus Northumbria School of Design \\ Graphic Design and New Media \\ Bina Nusantara University \\ Jakarta, Indonesia \\ bdirgantoro@binus.edu
}

\begin{abstract}
Nowadays, many people have left their country's traditions and cultures due to advancement of technologies. Indonesia is rich in diversity, also its traditional games that are an inseparable part of Indonesian culture that should be preserved. Traditional games are almost unknown and abandoned as children lack early knowledge because parents and teachers disregard their important role in teaching these games to children. Traditional games are not up-to-date and are replaced by modern and digital games. Moreover, children nowadays have less free time and are physically less active. Additionally, there are less fields to play nowadays. This project aims to re-introduce Indonesian traditional games by creating an interactive multiplayer table game about Gobak Sodor for Indonesian children from Generation $Z$, especially those around 9-12 years old. It also aims to overcome misconceptions that traditional games are not fun and increase interest on traditional games. The research methodology was done through literature studies, qualitative methods including site visits and in-depth interviews. Overall, the game can be a fun playing experience that can be played in limited space and time to re-introduce traditional games to children and encourage them to preserve Indonesian culture.
\end{abstract}

Keywords-Traditional games; Interactive games; Arcade game

\section{INTRODUCTION}

The world of children is the world of playing. Play is a need, especially for children, and therefore cannot be separated from children's lives [1] This is also because humans are "Homo Ludens", a concept that man plays games [2].

In the past, children of all ages like to play traditional games. However, it is very rare to see children from Generation $\mathrm{Z}$ playing traditional games nowadays, even in the villages, as the number of children playing traditional games diminished [3]. This is because children from the new generations, especially those who live in urban areas, have grown up depending on technology, the Internet, and social media. The development of modern and electronic devices makes traditional games almost unknown and abandoned as children lack early knowledge of Indonesian traditional games because parents and teachers disregard their important role in teaching these to the children.
Moreover, children nowadays are busier, have less free time to play and are physically less active due to their reliance on gadgets [4]. Additionally, there are less spaces or fields for children to play nowadays. Traditional games are not up-to-date and replaced by modern and digital games which are always created with lots of varieties and updated games and therefore are more interesting and addictive [5].

Gobak Sodor was one of the popular traditional games in Indonesia with its unique, interesting, and physically challenging gameplay that is not played nowadays. Moreover, the game does not require any equipment and can be played by all ages [6]. There are two roles which are defense and attack. The attacker moves from one end and must run to the other end while avoiding the defender. The attacker can move freely if he/she stays in the boundary of the game. The defender has a limited movement based on the line he/she picked, and they can stretch their arms to catch the attacker. The game ends with the highest score wins the round. Gobak Sodor helps children develop teamwork, motoric, cognitive, social, moral, emotional aspects, and intelligence [7]. It is chosen because it is a fun multiplayer game that is challenging and promotes social and physical aspects of traditional games.

To solve the problems mentioned, this project aims to reintroduce Indonesian traditional games by creating an interactive multiplayer table game about Gobak Sodor for Indonesian children from Generation Z, especially those around 9-12 years old, who live in urban areas and are digital natives. It will be a multiplayer game that involves physical movements and cannot be played alone to raise social values and physical aspect of traditional games. It also aims to overcome misconceptions that traditional games are not fun and increase interest on traditional game as well as encouraging children to do their part in preserving Indonesian culture. The game will be delivered in Indonesian language.

\section{LITERATURE REVIEW}

\section{A. Basic Elements of Game}

From its meaning, a game is a rule-based activity that will determine winners and losers. Game can also means as an interactive activity where players engage in a fun experience and 
face challenges in environments that require players to think on how to win [8].

Players interact with the game through game elements. The characteristics of game include having rules and competition to reach certain goals which may result to different outcomes [9]. A game should have goals according to the setting and make players struggle. Moreover, there should be challenges the player will face to engage the player and make the game enjoyable. Most studies agree that games should include a story, rules, levels with increasing difficulties, easy-to-play gameplay, interactions, rewards, objectives, audio, outcome, and high replay-ability. [10].

Game rules are one of the most important parts of a game. Game rules are binding and fixed. The rules of the game apply to all players and will limit players' actions [11].

Game audio is the last step of game production that plays a very important role, especially in arcade games. It increases engagement as it entertains players, enhances the experience, and also creates the mood and atmosphere [12]. Game audio can give additional feedback which are not shown on screen to players. Audio creates realism which results to faster reaction speed it helps to immerse players in the game and lets players feel the effect of their actions in the game [13]. Game audio includes diegetic sound like sound effects, character dialog and environmental sound, as well as non-diegetic sounds, consists of background music and sounds of interface outside the game world (Game Audio).

\section{B. Theories of Edutainment, Gamification and Educational Games}

There are requirements for educational games to be safe, appropriate for children's age, with clear shapes and audio, must have a function to develop aspects of a child's development and should be attractive [14]. Games can raise motivation, learning, and most importantly engagement in education [15].

According to the definitions of edutainment compiled by Aksakal [16], 'edutainment' is a word that combines entertainment together with education to increase learner's excitement and enthusiasm while learning difficult subjects. Furthermore, edutainment is defined as a type of entertainment designed to increase learner's excitement and making the process of learning enjoyable. In addition, Edu games are now mostly targeted to children in their early school years [17].

Engagement is necessary for learning experience. By using this method, children will be attracted by the game, become curious to learn and win it, resulting in them enjoying the fun experience, engage in the game and learning without realizing. In short, children will be attracted and addicted to the fun experience and rewarded with skills and knowledge in return.

Chris Crawford, a veteran game designer differentiates four types of play activities based on interactivity: Games are rulebased system in which the goal for the player is to win over an opponent whether the opponent is another player or computer. Puzzles, like Games has the objective to find the goal, but the difference is that puzzle's goal is to find a solution, not to beat an opponent. Toys are manipulative, but there is no goal. Stories involve role play, but they cannot be changed by the player as the creator already set the ending [18].

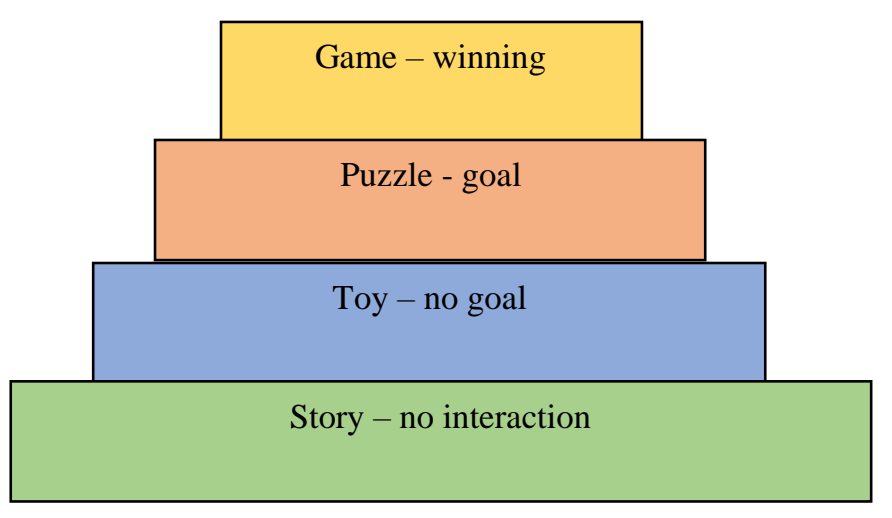

Fig 1: Four types of play, each built on the previous

The hierarchy above set the rule of thumb to design a game. As an example, we often call the card game Solitaire as a single player game but in fact, Solitaire is seen as a form of puzzle because any given deck has a definite solution or sometimes no solution and shuffling the cards can generate a newly randomize puzzle for the player to solve.

In creating the game, the mechanic has been set from the getgo. To recreate the authenticity of Gobak Sodor in a form modern digital game, the researcher investigates minigame mechanic. As stated by Scott Rogers, when designing the mechanic, we need to make sure that the control is simple adapting the easy-to-learn gameplay, keeping the play time short, and still need to feel satisfied when finishing the round [19].

\section{METHODOLOGY}

This research was conducted and supported by qualitative research methods. The qualitative research for this paper includes primary research such as in-depth interviews and site visits and secondary research such as literature reviews. Data were obtained from various books, e-books, journals, ejournals, articles from the Internet, site visits, and interviews. By gathering a variety of traditional games from books, the researcher came up with the choices of traditional games to be digitized into the arcade game. The content sources were mainly from different books and other game references because not every book contains the same information regarding Gobak Sodor history, gameplay, and rules.

For research purposes, observations were conducted by visiting three traditional games sites, Traditional Games Museums in Bandung, Komunitas Hong in Kalijodo, and Kampoeng Dolanan Nusantara in Magelang where a variety of Indonesian traditional games and toys are collected and can be played, and joined an event about preserving traditional games campaign to collect information, experience playing Indonesian traditional games and to observe and interact with target users. Additionally, the researcher joined a GameLab festival, and event held in FX Mall Senayan dedicated to research in Game and visited Educa Studio, A game publisher specialized in 
education located in Salatiga for an interview and studio tour to learn the game making process.

In addition, the researcher interviews with three traditional games experts who are Cacap Imansah, the coordinator of Komunitas Hong, Agatha, the secretary of Museum Pendidikan dan Mainan Kolong Tangga, and Abbet Nugroho, the founder and manager of Kampoeng Dolanan Nusantara to gain knowledge and their insights and opinions on the topic and the proposed solution.

Two game experts Dr. Alvanov Zpalanzani Mansoor, founder of Vistalab, and Andi Taru, founder of Educa Studio, were interviewed to gain knowledge on translating traditional game to digital game, tips, insights and opinions on the challenges, the solution, design, and important elements which should be in the game.

According to Nugroho, the age range of 5-7 is more appropriate as it is the golden age in children's development. In this age, they will be impressed, and the lessons will be planted in themselves for the future. He recommended congklak, bekel and can telephone to be digitized and to make a few games because there are so many traditional games. According to Nugroho, it will be a media of socialization through technology. He said that he is looking forward to the accomplishment of this project, that it will be useful and should be spread worldwide not only to Indonesian. From these interviews, it is concluded that most children like to play physical games that are challenging and that the game should not be mobile games and should involve many players to have social aspects like traditional games. Moreover, the researcher took note of the problem of lack of space and physical activity in choosing the game output.

For the design aspects, Alvanov emphasized that it is important for the components of the game to be in accordance with the original. He suggested that the visualization of the game should be according to its origin. He also mentioned that characters should have different roles and to have characters from different provinces as they will have different specialty and characteristics. For typography, he mentioned that rounded fonts are recommended and suggest considering the three principles of typography. Moreover, he mentioned that the colors that children like are pastel colors. Additionally, he suggested compiling references of games that children play nowadays and combine the visual style. However, it is up to the designer.

Qualitative research was done through in-depth interviews conducted for research purposes. Semi- structured interviews were conducted with the primary and secondary target users of the project which are children aged 6-12 to know their interests, experiences and knowledge Indonesian traditional games, the platforms and games they like to play as well as to gain their insights and perspectives on the topic.

The primary target of this project is Indonesian children between 9 to 12 years old of both genders, who are Primary 3-6 students regardless of their religions. The secondary target of this project is children between 6 to 8 years old and the parents of primary students. The social class of the target users are Middle to Upper-class.
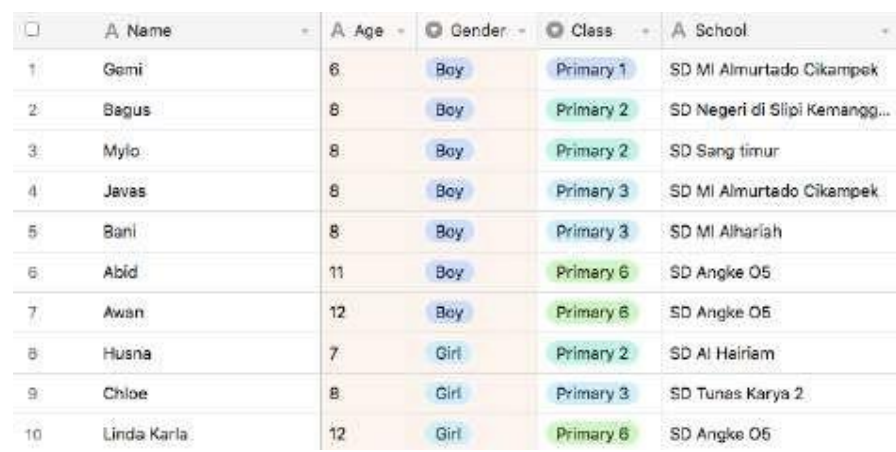

Fig 2. Target users' Interviews

The interview results stated that almost all interviewees know and played Indonesian traditional games but only half frequently play it. Moreover, the results showed that some interviewees were taught about Indonesian traditional games by their parents, some from their school and others from their friends. The results also showed that most of the lower-levels Primary students play traditional games during school break, while most of the upper-levels Primary students play after school.

According to the results of the interviews, not all Indonesian children and parents know and played Indonesian traditional games. Most of them only know few popular traditional games and prefer digital games. However, they are interested to learn and play more Indonesian traditional games and believe that Indonesian traditional games should be preserved.

\section{CREATIVE PROCESS}

The concept of the game will be war in different battle arenas in the past, present, and future inspired by the history of Gobak Sodor used in war practices. The visual style will be simplified sprite-style illustrations with no textures and less details because it is a top-down view game. Contrasting colors are used to differentiate the players' characters. Natural, warm, and cold colors are used to set the mood of serious war and battle to engage the target user. The game mechanics are inspired by the Soccer table game in combination with dancing game that use unconventional gamepad.

The signature posture of Gobak Sodor will be used as the pose of the defense team keeping their arms wide to defend their territory. Designed by Aurelia Pratama Siwi, the first design style attempted by the researcher were game sprites which are tall-built, proportional size and illustrated with flat, 2D cartoonstyle character design. However, it does not fit in the game as the characters need to be shorter and simpler to be seen clearly in the game and make the duration of the game longer as players need to move further to reach the goals. Thus, the researcher changed references and created new sketches to explore other styles of smaller, pixelated characters.

Next, the characters sketches were simplified into 2D Sprite design style which is simple and only uses cubes from the top perspective. Next, the character design was developed into different top-down views to differentiates the leader, defense team, and offense team. The refined characters design was also 
made to genderless characters because the character style made visually can be for both genders and arcade game characters are not customizable and should be for both genders. Then, the facial expressions of the characters were changed and experimented with different styles which are only using squares and the ones that are more stylized.

The weapons were first also sketched and designed in the pixelated-style illustrations by only using squares to illustrate the original weapon. As the characters were changed and developed into sprite-style illustrations, the weapons were then developed with shapes that have sharp edges. Moreover, the bombs to put in the goal by Player 1 were made for the present and future. The colors of the weapons and characters were adjusted according to be clearly seen on top of the settings background.
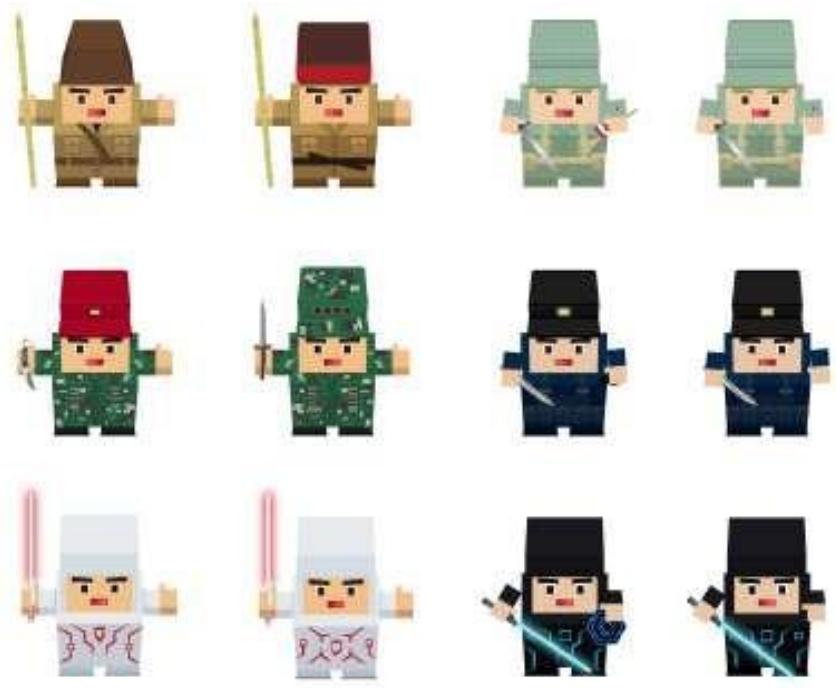

Fig 3. Characters and Weapons Design

The settings design will involve tiles and squares which are used in many popular game designs like Clash Royale and Plants Vs Zombies. The tiles where players of the defense team will be indicated with different tile colors. The researcher explored and compared which color contrast and pattern is best to be used. However, since the game atmosphere and settings should represent the real world, the colors and objects in the game were added according to real life objects in the simplified sprite-style illustrations. Later, more assets were added and modified to topdown view considering each of the player's view.
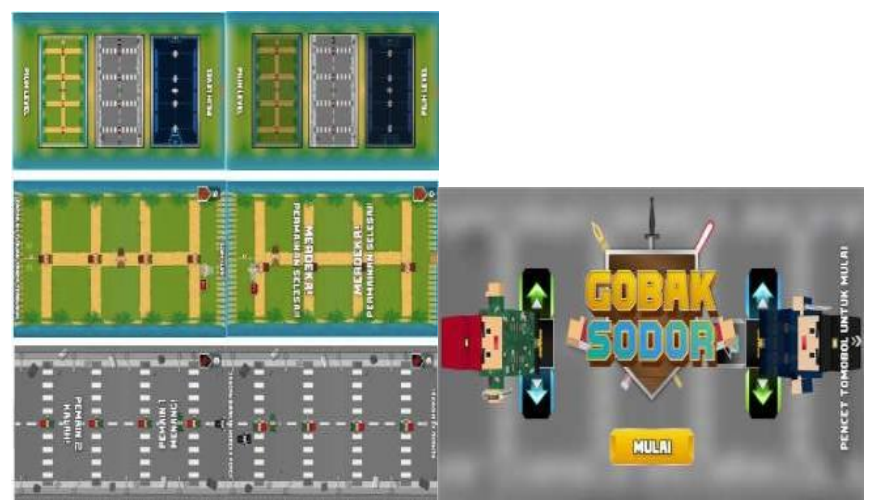

Fig 4. Final Game Screens

The researcher created several game prototypes with unity playground assets in UNITY before creating the final game. The researcher explores the mechanism that unity playground can do that is to control the sprites' movements with arrow keys and W, $\mathrm{A}, \mathrm{S}$, and $\mathrm{D}$ button on the keyboard. In the 1st prototype, the controllers, goal, health, score and few colliders that limit player 2's vertical movement worked. Player 1 was given 5 health, if Players 1 and 2 collide Player 1 will lose 1 health, if Player 1 lose the prototype shows a game over User Interface.

A user testing was conducted to measure the preferable height of the table, screen size for the target user and size of the stomp pads. The researcher measured the feet and height of the 4th Grade student, Chloe and ask if the screen, table and game pads measurements are comfortable for her. The height of table and screen size are where comfortable for her, and she thinks that the game is fun, but it is difficult for Player 1 to win. Also, the stomp pads were too small for her to stand in the middle. In the 5 th prototype, the temporary assets were replaced with the game assets made to check the mechanics, colliders and see how the game looks and works with static characters. However, the UI were not changed yet.

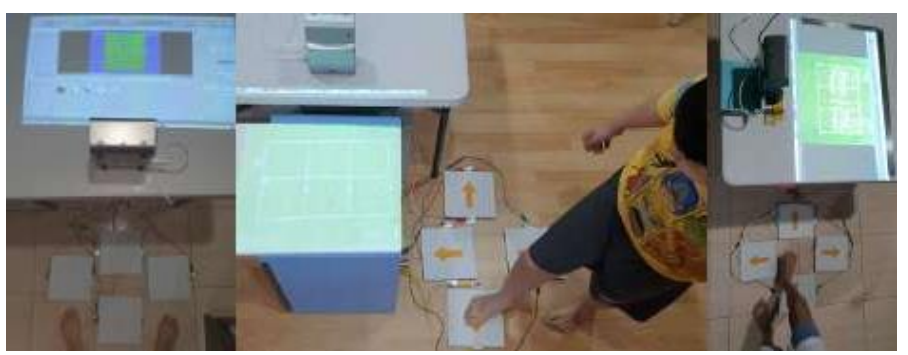

Fig 5. User testing

For the 2nd user testing, the objective is to test multiplayer table game and the finished stomp pads made of wood. However, only the stomp pads for Player 1 were pasted with the design they chose out of several alternatives the writer made. Their preferences for the logo were also considered in choosing the final logo. The writer also asked them if they like the visual style of the game and they liked it, but the characters were too small on-screen. Moreover, they want the speed to be faster because the Makey needs few seconds to work.

They also mentioned that some stomp pads do not stay in place and does not work sometimes. This is because of the 
thickness of wires and lack of aluminum foil for the stomp pads. However, they keep playing the game and proven enjoyable.

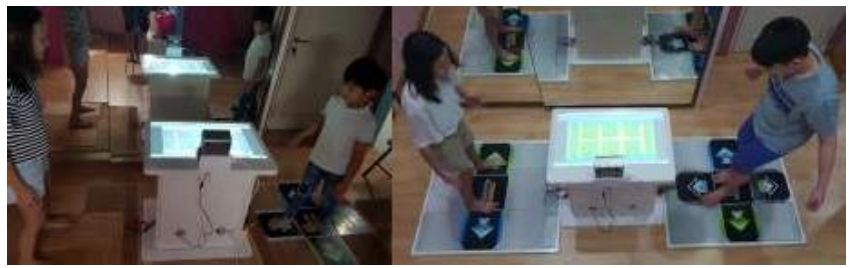

Fig 5. Multiplayer testing

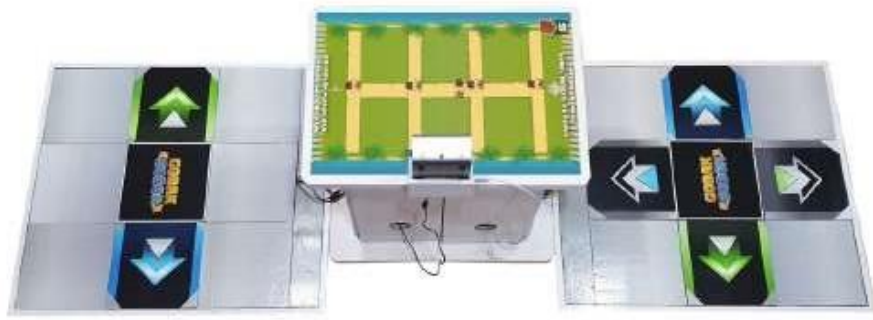

Fig 6. Final Arcade Game Design

\section{CONCLUSION}

In conclusion, the existence of traditional games like Gobak Sodor has been abandoned and not passed down to the nation's next generations that are responsible of preserving Indonesian cultures including its traditional games. Traditional games are considered as ancient game and are replaced by digital games. Furthermore, children nowadays have less free time and are not as active as the previous generations.

After doing researcher and coming up with different digital games idea and media, the writer decided to create an interactive multiplayer table game to re-introduce the Indonesian traditional game of Gobak Sodor to the target users. The researcher changed the final output into an arcade game because mobile games have more negative effects on children as it makes them addicted and physically inactive.

The concept of the game was based on the history of Gobak Sodor being used for war training. During the development process, it shows that the fun and challenging gameplay engages players and attract other people in the surroundings to play the game.

Lastly, the game went through many stages of game testing and user testing starting from its prototype to arcade game making process. Hopefully, this game will be useful for children of the new generations to learn and preserve Indonesian traditional games as well as for entertainment. There may be future possibilities for the game be further developed, updated, and go international.

\section{REFERENCES}

[1] Rahmawati, D., \& Destarisa, R. (2016). Aku Pintar dengan bermain. (F. Pondrafi, Ed.) Solo: Metagraf.
[2] Wahyuni, D. T. (2018). Pendidikan Karakter dibalik permainan tradisional yang mulai terlupakan.

[3] Novi Mulyani, M. (2016). Super asyik Permainan Tradisional Anak Indonesia. (P. Uta, Ed.) Yogyakarta: Diva Press.

[4] Hasanah, N. I., \& Pratiwi, H. (2017). Pengembangan Anak Melalui Permainan Tradisional. Yogyakarta: Aswaja Pressindo

[5] Yusuf, S. M. (2018). Pembelajaran Menyenangkan dengan Permainan Tradisional. (Istiqomah, Ed.) Surabaya: Cipta Media Edukasi

[6] Tim PlayPlus Indonesia. (2016). Ensiklopedia Permainan Tradisional Anak Indonesia. (P. Fitrisia, \& W. Rachmayanti, Eds.) Indonesia: Penerbit Erlangga

[7] Novi Mulyani, M. (2016). Super asyik Permainan Tradisional Anak Indonesia. (P. Uta, Ed.) Yogyakarta: Diva Press.

[8] Wiana, R. D., M., I. R., \& Mansoor, A. Z. (2012). Perancangan Game "Galah Asin" untuk memperkenalkan budaya tradisional Jawa Barat. Jurnal Komunikasi Visual \& Multimedia, 4(2), 73 86.http://journals.itb.ac.id/index.php/wimba/article/viewFile/10833/4019 [Accessed Sept. 12, 2020]

[9] Nani, D. (2018). Ayo, Main Bareng! (A. Mu'min, Ed.) Jakarta Timur: Penebar Plus+.

[10] Deterding, S., Dixon, D., Khaled, R., \& Nacke, L. (2011, September 30). From Game Design Elements to Gamefulness: Defining Gamification. Available: ResearchGate, https://www.researchgate.net/publication/230854710_From_Game_Desi gn_Elements_to_Gamefu lness_Defining_Gamification [Accessed Aug. 09, 2020]

[11] Kronisch, D. C. (2016). Gamification - Concepts and Theories. Retrieved February 2020, Available: academia,https://www.academia.edu/24042745/Gamification_Concepts _and_Theories [Accessed Sept. 12, 2020]

[12] Ghanavi, R. (2018). Assignment 1 - Video Game Audio. Retrieved May 2020, Available: University of Sydney, https://ses.library.usyd.edu.au/bitstream/handle/2123/19862/DESC9117 $\% 20$ Assignment $\% 201$.pdf? sequence=3\&isAllowed=y [Accessed Sept. 2, 2020]

[13] Ghanavi, R. (2018). Assignment 1 - Video Game Audio. Retrieved May 2020, Available: University of Sydney, https://ses.library.usyd.edu.au/bitstream/handle/2123/19862/DESC9117 $\% 20$ Assignment \%201.pdf? sequence=3\&isAllowed=y [Accessed Sept. 2, 2020]

[14] Russell, D. (2012, April 19). Video Game Audio: Diegesis Theory. Retrieved May 2020, 2020, Available: http://devmag.org.za/2012/04/19/video-game-audio-diegesis-theory2/27 [Accessed Dec. 1, 2020]

[15] Alaswad, Z., \& Gillern, S. V. (2016, January). Games and Game-Based Learning in Instructional Design. Retrieved February 2020, Available: ResearchGate,

https://www.researchgate.net/publication/336767478_Games_and_Gam e-Based_Learning_in_Instructional_Design [Accessed Aug. 5, 2020]

[16] Aksakal, N. (2015, May). Theoretical View to the Approach of the Edutainment. Retrieved December 2019, available: Researchgate, https://www.researchgate.net/publication/277964389_Theoretical_View _to_The_Approach_of_T he_Edutainment [Accessed Aug. 5, 2020]

[17] Egenfieldt-Nielsen, S. (2010). Beyond Edutainment: Exploring the Educational Potential of Computer Games. Retrieved December 2019, available: GoogleBooks, https://books.google.co.id/books?hl=en\&lr=\&id=snupBAAAQBAJ\&oi= fnd \&pg $=$ PA9 \&dq=theori

es+of+edutainment+\&ots=0rUwVFa0oy\&sig=I5igVB7jaX8sIkwR66IU f3LE8-

o\&redir_esc $=\mathrm{y} \# \mathrm{v}=$ onepage $\& \mathrm{q}=$ theories $\% 20$ of $\% 20$ edutainment $\& \mathrm{f}=$ false [Accessed Nov.16, 2020]

[18] Fullerton, Tracy (2008), The Structure of Game," Game Design Workshop- A Playcentric approach to creating innovative games 2nd edition" United States.

[19] Rogers, Scott (2010), Level 12- The Nuts and Bolts of Mechanics, "Level Up- The guide to great video game design" United Kingdom. 